\title{
Chapter 3 \\ The Same Tone, but a New \\ Sound-Understanding the Story \\ of the Soul as Pathway to Regenerative \\ Civilizations
}

\section{Christa Zettel}

\begin{abstract}
This chapter takes not only into a historic perspective that looks at human consciousness development over many millennia, but emphasizes the importance of mythology as the most deeply ingrained way of humankind to keep learning for transformations. The author argues, contrary to the modern mind's needs, that the creative aspect of change or transformation is not order, but disorder or chaos. To avoid the final fragmentation or destruction of our world, the intuitive 'universal power of self-renewal' (the life instinct) needs to be reintegrated into rational science, to fill our scientific particularization (the death instinct) with meaning, which is adequate to living in a humane way on our planet. This makes the story of the soul (Greek: psyche), which is passed on by peoples and cultures in a nonlinear-out-of-timeway, not only an important resource to understand the entire civilizational process and subsequently the development of regenerative civilizations. By allowing the forthcoming of an innate integral structure in the human mind, which uses both rationality and intuition, creative mythology is a discipline important for transformation literacy. It can contribute to the so much needed acceleration and speed up the process of collective regeneration, because this is a creative act and unleashes what was previously impossible.
\end{abstract}

Keywords Creative mythology $\cdot$ New enlightenment $\cdot$ Spirit and mind $\cdot$ Mind and matter $\cdot$ Archetypes and consciousness $\cdot$ Selfrenewal $\cdot$ Geist-in-action

\subsection{The Story of the Soul}

There is an inherent tendency in people who aspire to contribute to a transformation of our world to only take the present as a mental starting point for the creation of a different future, without understanding the historical lineage of mythical structures that underpin the present collective and individual behaviour. This article argues that the immersion with the story of the soul, and its manifestations in mythical

C. Zettel $(\varangle)$

Sonnenweg 9/8, 7122 Gols, Austria

e-mail: christa.zettel@bnet.at 
structures is crucially important to contribute to and mobilize the consciousness shift so necessary for humankind's prospects of co-creating a liveable future. Science has so far widely neglected the role of the human mind in manifesting future. However, the increasing calls for transformations to sustainability and more regenerative ways of living on our planet are an indication that a new cycle of evolution, one which includes the transformation of the human psyche, has already started.

In the year 1981 in his studies about human consciousness, Jonathan Sheara professor of philosophy in the USA - presented the results of a research project with hundreds of participants from different cultures and religions, practising the formula 28 of the Indian Master Patañjali who lived approx. 500 B.C., by using his star-like diagram for meditation (Powell, 1989). The text of the formula reads: Who concentrates with the inner mind (samyama) on the polar-star, gains knowledge about the rotation of the stars. In fact, all people meditating, reported that they could see the polar-star at the end of a long and circulating pillar of light, releasing light beams, similar to the ribs of an umbrella. This umbrella-like image, in which the stars seem to be interwoven, appears also circulating. More umbrella-like images, one packed into the other, could be seen next to the light pillar. Each seemed to circle with its own speed, had its own colour, and produced a clear, wonderful tone, experienced by all participants and described by them as: magnificent, blessing, bright, and comforting (Powell, 1989, pp. 72-73; Shear, 1981, p. 73).

Jonathan Shear (1981) drew attention to the fact that the graphic images, seen in the course of this meditation, correspond with the geometric images, described by Plato (375 B.C.E./1973) at the end of his publication 'De Republica' in the myth of 'Er', 1 who dies, flies up into heaven, and returns in his body to talk about his experiences. Powell also concluded, the meditation awakes non-learned, endogen (inward created) reactions, which one can call rightly an innate archetype or an innate structure of the human mind (Plato 375 B.C.E., p. 616b-e, as quoted in Powell, 1982, p. 78). This knowledge of awakening such an innate structure is part of the cultural heritage of our ancestors, passed on in their stories and practices. What Joseph Campbell (1968) called 'Creative Mythology' can be used as a tool to bring into the light of our consciousness a new, but at the same time already, innate psychic reality, which may enable us to find new solutions for world problems, and pathways into a future in which development does not benefit anymore only a privileged minority, but humanity as a whole. This may seem to many as an illusion or wishful thinking, but I believe it is an underestimated pathway to the emergence of a new way of enacting futures, because what can be described as the story of the soul (gr. psyche) in a nonlinear-out-of-time-way is also the process of the development of the 'psychomental body', which the French Philosopher Henri Bergson (1911) described already at the beginning of the last century as process ontology, called 'civilization'. He vehemently argues for the unpredictability of the evolutionary process which can only be understood by not only using our rational mind, but also fostering our intuitive

\footnotetext{
${ }^{1}$ The Myth of Er is a legend towards the end of Plato's Republic (10.614-10.621). The story includes a view into the cosmos and a narration about the afterlife experiences. See: https://en.wikipedia. org/wiki/Philosopher_king, accessed 2 May 2021.
} 
capabilities. In his view, the mysterious origin of everything is omnipresent in the story of the soul, similar to a symphony in which the ground motive of the first accord returns as mighty final cord. The goal of the soul is, however, not physical extinction, but to reach a transcendent state of being, allowing rebirth. The same tone, but a new sound!

\subsection{The Flow of Consciousness, History, and Mythology}

According to Jean Gebser (1978), all peoples (and because of the fundamental biogenetical law all individuals) have to develop in the course of their history of culture five structures of consciousness which he calls: archaic, magic, mythic, mental and integral. Each structure reflects another psychic quality of human existence. None is better or worse than the others, and all are contained in the sub-consciousness (Illies, 1978). The archaic structure is represented by the prehistoric Mother Goddess as a symbol for the sub-consciousness, in which the 'I' as the focus of attention was still deeply embedded in the wholeness of the collective and all that it surrounded. For the ratio (the mental structure), this is perceived as a primitive or even obscure state. However, it is important to consider that what for the ' $\mathrm{I}$ ' is the furthest away in time, may touch the soul the closest and reveal the story of the soul mentioned above!

As Thompson (1985) stated in his book about mythology, sexuality and the origin of culture, for the 'I' the consciousness of time seems to work linear: past-presencefuture or diachronic, but for the soul, time is omnipresent or synchronic (LévyStrauss, 1966, p. 237). Because the soul exists out of time, she is able, if allowed by the 'I', to look at the same time backwards and forwards (Thompson, 1985). This is noteworthy, because this would mean that the stage for a fundamental mind-change is not the conscious ' $\mathrm{I}$ ', but the sub-consciousness level of the soul (Harman, 1998). While man in the next state of a magic structure of mind can still have a direct revelation (gr. apokalypse) of 'God and the World', at this mental structure there is already the new tendency emerging: he begins to be convinced only he (e.g., in the role of a king, in the enlargement of his 'I' by speaking on behalf of his people) can have it.

The following next state of the mythic structure is based not anymore on a cult, but depends on the relation of the individual to the respective social organism, and on the feeling of identification with a revelation that includes all people who share a common mythology. Whenever a culture (or an individual) is ready for the next following structure of consciousness, chaos erupts. The psychic power, enforcing change, turns against the old order. The result is a psychic crisis, because what has been the greatest achievement of the old order, becomes the greatest enemy for an evolving, but still unconscious new order. Such times are described in mythology as 'Dark Ages', accompanied by mass migrations, a 'War of Cultures', nature disasters and climate changes, which are always periods of regression in culture, because the ability to adapt to an ecological niche, demanding a new adjustment, requires the entire psychic energy of the people (Thomson, 1985). After the last Dark Ages, 
known as 'Trojan War', the next state, the mental structure was established in Greece, while in the Near East a 'new mythology' was transcribed, which became the psychic foundation of the European or occidental civilization.

Hence, in variation of transcriptions, mythologies are passed on throughout human history. To give one example for the continuance in mythology: what Greek stories told about Sisyphus and Tantalos, the two greatest sinners or tyrants in Hades, the underworld or sub-consciousness, find its equivalent in Egypt. Egyptian writers anticipated in the story of the fight between Horus and Seth, the unification of Lower and Upper Egypt and impressed onto the collective memory of this High Culture from her beginning to her end. Such is the power of mythological stories and archetypes, ${ }^{2}$ passed on since prehistory in rituals and preserved by rock-engravings, rock-paintings and last but not least by oral tradition. Because the story of the soul looks on history from a holistic point of view, she does not separate between similar occurrences in time or locality, but combines them to one great story, to show a development, shared by all people. How the story of the soul is understood and passed on depends on the level of consciousness, which a tribe or nation has reached at the time of formulating their history of origin and rise. Over the course of millennia, and the emergence of the subsequent mental structures, the longing of the soul to experience embodiment as a transcendent state of being became obscure. This is why Ken Wilber (2001), the founder of Integral Psychology, noted that how people view reality is a composition of various levels of existence - matter, body, mind and soul. As individuals, people pass, if not struggle, through the different levels of mental structures and reach a higher state of being. Earlier states are present and not just infantile experiences. In various constellations, collective consciousness also passes through the different stages of consciousness development.

\subsection{Archetypes and Their Shadows in Modern Society-Dionysus Versus Apollon}

If we followed the suggestions of Jung (1983), we would consider mythical figures not just as mortal humans, who belong to a certain time and locality, but as archetypes, which structure the story of the soul and subsequently, the emotional dimensions of life. This would help us into the realization that any stage of consciousness development generates its own match with the story of the soul. By recapitulating the old and presenting the new story, this process becomes the overture of what is still to come (Thompson, 1985). Interestingly, Jung's Quarternion of Archetypes-King (Queen), Lover, Warrior, Magician—resonates with people on a strongly emotional level, and it has been used in leadership development (Kuenkel, 2008). But the currently most dominant state of mental structure, the ratio, tends to consider them

\footnotetext{
${ }^{2}$ What the ethnologist Adolf Bastien (1826-1905) called "Elementargedanke" (elementary ideas), Jung (1983, 1995) called "archetypes of the collective sub-consciousness, which structure the emotional dimensions of human life.
} 
to be meaningless, or degenerate them into a tool for learning how to lead, devoid of their depth. However, as components of the structure of consciousness, they represent vital important psychic powers, essential for the building and sustaining of any society. The integral power in the centre of the psychic world is the Sovereign or Lord (Jung's term in German is 'Herrscher' or 'Herrscherin'), who integrates the powers of both King and Queen, and accepts and mobilizes the power of the other archetypes: Warrior, Lover and Magician, while bringing the necessary sacrifices for the benefit of the entire Quaternion. The Warrior is a symbol for the yang-side of the King, the Lover of the yin-side. The Magician, symbolizing the being and technology of the material world, governs also the immaterial world and connects as Shaman, Magus, Alchemist or Priest, the two worlds, yin and yang. Only the integration of the yangand yin-qualities of the archetypes make a strong sovereign into a good sovereign, as wise as King Salomon. However, if these archetypes are suppressed or neglected by society, they go underground, in the sub-consciousness. This has tremendous effects on society, because their psychic energy becomes split into shadows, which manifest themselves as polarities, with one excessive side, while the other one lacks the necessary energy of the archetype (Jung, 1983). According to Bernard A. Lietaer (2000), associate professor for Archetype Psychology at the Sonoma State University in California, the part of the King is played in modern western societies by governments; military forces and enterprises represent an important part of the Warrior; Universities, Science, Technology and Rationality have partly taken over tasks of the Magician, without necessarily integrating yin and yang, while the archetypical Lover, expressed in the arts, is mostly restricted to private life. Suppressed into the sub-conscious underworld and ignored by society, archetypal shadows emerge in the too strong or too weak extremes, often split into the binary polarities, for example the tyrant versus the softy (King); the sadist versus the masochist (Warrior); the sex-possessed versus the impotent (Lover), and apollinic-hyperrational versus the dionystic arbitrary (Magician). Pushed into the unconscious, the shadows become invisible actors: the hyper-rationality of the Magician shadow can be easily recognized in our technocratic society with its focus on a particular production of facts and knowledge, coupled with the belief in omnipotence and truth, and the assumption that it is possible to be absolutely rational and objective (Lietaer ibid.). But also, the dionystic extreme of the Magician shadow assumes to be in possession of the only possible truth, even if it may be different from the hyperrational truth of its opponent. This observable dynamic of righteousness suggests that we should consider Norman Brown's advice, that time is more than ready for the mystic to break the mirror through which he sees everything dark, and for the rationalist, to break the mirror, through which he sees everything bright, to allow both to enter the kingdom of psychological reality (see Brown, 1959). 


\subsection{The Ultimate War-Eros and Thanatos}

When we take a perspective on consciousness development over the span of several millennia, we can observe that our world is a man's world, dominated by unconscious male archetypes. The inner Queen or female Self, called by Jung Anima (Jung, 1983), has been suppressed for many centuries. In archetypes and art, she re-emerged in France at the end of the tenth century as 'Black Madonna' (also called the 'The Egyptian'). ${ }^{3}$ James Hillman (2004) suggested that understanding this archetype may reconnect us to the story of soul so that the image of the Black Madonna symbolized the positive power of the depression, because she forces us to look inside, so that we can find the soul. Which remained from this first attempt to reintegrate the female Self into Christianity was, besides the story of King Arthur and the legendary Grail, the first original myth of the Occident, the story of the love of Tristan and Isolde in the twelfth century. For the understanding of the significance of reintegration female archetypes into human consciousness development, it is worth to have a closer look at their story, for which many variations exist. In the interpretation I follow here (Johnson, 1985), Tristan is the prototype of modern man. Tristan, the sad-born child of the occident, has to fight a tyrant, the shadow of a King (the male self or Animus according to Jung), who has no inner Queen (or Anima) anymore. He wins the battle, but then he has to fight against the monstrous brother of the Queen of Ireland, whom he kills. But he was wounded by the giant's poisoned sword. Because the wound cannot heal in this world, he sails to the shores of Ireland, where the giant's sister rules, because only Isolde, the daughter of the Irish Queen, can cure him. They fall in love, but unfortunately, Tristan and Isolde try a drink, prepared by Isolde's mother, a famous magician, which was not meant for earthly lovers, but for the inner or psychic marriage of King and Queen. That's why Isolde is described as the only woman in the world, who can cure Tristan. But at the same time, she is the only woman in the world, who wants his death, because he killed her mother's brother (Johnson ibid.). The story symbolizes that the female archetype (or Anima) can work to the benefit of man only at the right place, in the delicate space between the rational 'I' and the mythical sub-consciousness, which allows the mind to explore new dimensions of being. Yet, if this space is not explored, the female archetype tends to be placed between the 'I' and the man's world and is perceived as a threat. By ways projection of this threat on any mortal woman, the female archetype is perceived to overthrow the 'I' of man by using his own weapon, the sword, flooding his psyche with demons or projections. In this case, the Anima does not lead the way to human feelings, but instead leads away from them, making humaneness inhuman, and in the worst scenario is perceived as eliminating the 'I' of man (Hillman, 2004).

This story hints to underlying mythical forces: Greek philosophers called the archetypical function of love or the longing for love, Eros, representing the life instinct or life force, and its polarity Thanatos, the Greek symbol for the death instinct.

\footnotetext{
${ }^{3}$ Black Maddona's can be found in many countries in the world. Some research suggests that their origins are related to the queendom of Sheba in Africa (Begg, 2006).
} 
Both emerge from the sub-conscious. Freud $(2017)^{4}$ considered the life instinct or Biophilia and the death instinct or Necrophilia as equal strong psychic forces. But Erich Fromm (1977), exploring the anatomy of human destructiveness, suggested that only the life instinct is a normal biological impulse, while the death instinct represents a rather psycho-pathological relevant symptom, created by culture and civilization. This pathology becomes stronger, the more the life instinct is suppressed by society, until - in the worst-case scenario-it is left as the only possible pathway. It is quite revealing to compare the qualities of the life and the death instinct, as described by Erich Fromm. He suggests that humans driven by the life instinct are future orientated, prefer to build up something new and are not captured by a past, which man, driven by the death instinct, wants to keep at any cost. They do want to be more (life instinct) and not to have more (death instinct); enjoy life in all its manifestations, and are not driven by the lust for consumption or for daily sensations (which is a manifestation of an obscured death instinct). For Fromm, individuality works best in a collective that encourages its members to be self-creative. In our modern societies, ego-centredness of individuals (a symptom of the death instinct) dominates reality and replaces the wellbeing of society. This throws individuals into a dilemma: the only psychic possibility left to an individual to escape the prison of this dominant egocentrism and his exclusion from a self-creative activity is to adapt to the dominant form of Thanatos, to the death instinct, which takes life away (Fromm ibid.). In the mythological story, these two instincts are intertwined. Tristan does not have to die to be re-united with his eternal love Isolde. Seen from the point of view of the mortal 'Body-I', Eros wants to maintain the life essence, while Thanatos strives for an end. In a different interpretation, both instincts can work together. If one considers Eros as the impulse to experience during lifetime the highest possible state of love and awareness, Thanatos can be understood as the inner impulse to reach new dimensions of consciousness by the death of the normal day-awareness. The Eros dimension of man, the joyful to-live-in-this-world, can exist and work together with the Thanatos dimension, the inner wish to reach higher levels of consciousness, to experience spirituality (Boorstein, 1988).

\subsection{GEIST-in-Action-The Co-creative Power of the Mind}

C. G. Jung has not only introduced his Quaternion of Archetypes into the modern 'science of the soul'- psychology, he also reintegrated what was known until antiquity as the 'Universal Soul' into the sub-consciousness (connecting individual, collective and universal level). Roger Penrose (1989)_a theoretical mathematician—noted that physicians while searching for the origins of life, will finally come across the roots of consciousness, and for the biochemist Rupert Sheldrake (1985), who has introduced

\footnotetext{
${ }^{4}$ Todestrieb/death instinct was first mentioned by Freud (1920) in his book 'Jenseits des Lustprinzips' (1920, 2017); Freud suggested the terms life instinct or Eros and death instinct; Fromm analysed Freud and introduced his new terms biophilia and necrophilia.
} 
his theory of morphogenetic fields in nature-sciences, it is imaginable, that similar to the electromagnetic field of our planet, of which our biosphere is part, the relation between the individual and the universal part of sub-conscious powers could act as ideal mediator in a hierarchy of fields. This would suggest the conclusion that also Gaia (the Earth) has something like a spirit, embedded in the spirit of our sun-system and beyond this instance in a kind of galactic spirit. How this connecting 'spirit' is understood, may be different in different languages. As writer, I could not fail to notice that in my mother language (German) the word Geist does not distinguish between mind (the way how we think) and spirit (soul). The interconnectedness of our troubled biosphere, in which all continents and seas are situated, on or in which all species on Earth, including humans, live, is already well documented by nature sciences. But although the dramatic consequences of the ignorant and egocentric behaviour of modern societies in the Era of the Anthropocene have been described and predicted by science since long, the role of the human mind in its relation to the spirit of the Earth in the entire process of our emerging planetary crisis is not in focus. In fact, the role of the human mind is not only badly understood but underestimated to such an extent, that it threatens to extinguish life from our planet (Vernadsky, 2006). There are, however, various insights that hint to the significance of this issue. The intrinsic connection between mind and matter has been illustrated many times: by Vernadsky's (ibid.) mathematical formula, Sheldrake's (1985) morphogenetic fields or the theoretical physician David Bohm's model of an 'implicate order in an enfolded universe' (Bohm, 1980). Also Ilya Prigogine (1996) recognized cosmic dimensions or co-evolution in nature as the cause for a synchronic development of micro- and macro-scales (Briggs \& Peat, 1990). Archetypes can be interpreted as representations of the human connection to an underlying spirit, because they belong to sub-conscious regions. They cannot be separated from the forces which created nature and the biological anatomy of humans, glands, organs, brain and the central nerve system (Lietaer, 2000). Kant said that the laws of space are known to the human mind, because they originated in mind. They are part of a knowledge, inherited by birth, a knowledge a priori, which can be remembered in extraordinary circumstances (Boorstein, 1982). While the 'I' needs the ratio to understand reality, the soul (psyche) needs symbols to 'remember'. Because nothing can be a symbol, which was not once an object of experience, it does not matter what symbols show, a figure (mathematic), a letter (alphabet), objects (stones) or tones (music), to cause a sub-conscious reaction in the mind, a memory of the story of the soul (Rudhyar, 1979). From such a systemic view of the world what applies to natural systems, also applies to the human mind (Capra \& Luisi, 2014). Especially in Eastern philosophies and mythologies, a reciprocal action is assumed between the smallest and the greatest. The individual self relates to the collective self in a similar way as, e.g., in macrocosmos the polar axis to the equator (Campbell, 1992, 1996). Like in nature, the macro-cosmic north and south poles build an axis, which according to astronomic and telluric facts regulates the flowing in and flowing out of cosmic magnetic energies. In body-mind practices such as yoga practised since 4000 years, the human spine is the axis, through which the flow of spiritual energies is regulated by the central 
nerve system of the human body. ${ }^{5}$ This happens with the help of an invisible channel (the nerve centres or Chakras), called Sushumna (Woodroffe, 1974). This can help to understand the mystery of the polar-star-Sutra meditation mentioned at the beginning.

This relationship between mind and evolution was researched by the Russian nature-scientist Vladimir Ivanovich Vernadsky, who published his findings already in 1926 (reprinted in 1998), introducing his theory of a 'Noosphere' in relation to the biosphere of our planet, a concept that can be seen as crucial to understand the role and help of the human spirit for transformation. Vernadsky described the noosphere as a kind of creation-state before any separation (duality) has taken place. It is a physical vacuum or ethereal 'in-space-element' (within the earth atmosphere), which can become visible or remains invisible. He predicted the endangering influence of the human mind on the biosphere, but also suggested that the future evolution of the planet was dependent on "increasing consciousness and thought, and forms of having greater and greater influence on their surroundings" (Vernadsky, 1998, as quoted in Steffen et al., 2007, p. 615).

Plato used the word ethereal to describe a mysterious element, known in Egypt as $\mathrm{Ba}$ within the trinity of the soul: Akh (universal) - Ba (ethereal)-Ka (astral or life essence), which reminded Thompson (1985) of Jung's trinity of the subconsciousness (universal, collective and individual). Ka can be understood as that part of personality, in the sense of a uniqueness of a person, that would live on even after death, while Ba can also refer to inanimate matter. Described in antiquity as 'breath of God', what Plato called 'ether' is equivalent to the Hindu word prana, which expresses a life force or vital principle. According to Eastern tradition, it has a dipole to the kundalini (life essence) in the human brain. Other authors also argue that there is an intrinsic relationship between the individual and the collective. For Rupert Sheldrake (1985) memory is an inherent feature of evolutionary processes in nature. The 'collective memory' of the planet is built up by a process of formative causation through what he describes as morphogenetic fields that create morphic resonance, hence reality co-develops in relationality. He argues that this leads to similar action even at a distance and is not limited to space and time. Interestingly, there are similarities with what Jung called the collective unconscious. Sheldrake suggested every human being is endowed with this knowledge about the unconscious since birth, and it is structured by archetypes as mythological motifs or primordial images. This makes particular sense, if one considers the concept of energy fields, mentioned by Oschmann (2016), which are created by natural or artificial rhythms. They cause an entrainment of biological rhythms, which in turn influences the speed with which the human nerve system reacts to impulses or stimulation.

What the above journey through the centuries of exploration in the mind and matter relationship shows is that our minds are not only connected with the collective unconscious, as Jung would call it, but through this vastly distributed consciousness, with each other. Moreover, the act of co-creating reality is a constant process of becoming conscious. Something becomes visible, when we become conscious of it.

\footnotetext{
${ }^{5}$ Campbell mentions that the classical Yoga (mulasbandhasana) goes back to the Indus culture about 2300-1750 B.C. (Campbell, 1992, p. 91).
} 
This is illustrated by a mythical story. Heracles (roman Hercules), the proto-Hellenic hero of the Mother Goddess (Hera), has to fight against the monstrous Hydra. But he cannot kill her, because as soon as he cuts off with his sword one of her nine heads, three others grow instantly to replace them. In his despair, he remembers the words of his wise teacher: We grow, when we kneel down, we win, when we put aside our weapons, we receive, when we give. Heracles kneels down to the swamp, in which the monster lives, and lifts it up into broad daylight. Now he can cut off all nine heads. As soon as this is done, a tenth, before invisible head of the Hydra becomes visible, shining like a precious diamante. So, in the end, the monsters against which the innumerable heroes of our myths have to fight against, yield something precious, hidden in the sub-conscious Self. This suggests that we need to become much more conscious about how intrinsically linked mindsets and reality creation are. Moreover, both manifest in structures of societies, and these structures are linked to mythical stories and related archetypes that influence behaviour through the collective unconscious.

The relation of a society with mythical figures, archetypes and the access to the collective unconscious can have practical historical consequences. Lietaer (2000) has drawn attention to the fact, that in our entire history only two eras are known, during which at the same time a high standard of living for the population and a flourishing culture existed. One was the era of the European High Middle Age in France, the other one, lasting at least 1500 years, was the Egyptian High Culture. In both cases, the prosperity of the collective correlated with the flourishing of the female archetype. For example, Egypt had two types of currencies to ease trade in a way that would also benefit society. What can be called the yin-currency was used locally, while the yang-currency in the export trade. Although a demurrage charge, a fee on currency not used, was established, it did not diminish the currency as such. However, for example, when 10 bags of corn were stored by an owner, he was returned only eight. This avoided any attempts to hoard based on greed or hope that prices would increase. In both historical era, the reason for interruption and financial breakdown, followed by chaos, dissolution and the return of an elite, was the declining of the female archetype; during High Middle Age, it was the demise of the worship of the 'Black Madonna'; in Egypt, it was the ending of the cult of the goddess Isis. Much too little research has gone into the understanding of the depth of the relationship between mythical mental structures - such as the female archetypal structure and the functioning of human societies.

Today, in the year 2020 A.C., with the severe global sustainability challenges we face, and the slowness with which politicians, decision-makers and ordinary people respond, it is obvious that the underlying archetypal structure is determining the mindsets and subsequently, behaviour. The shadow of what Jung would have called the inner Magician tends to serve a Shadow-King, who with his help wants to avoid truly transformative change at any cost and instead strives to prolong his glorious past into the future until eternity. However, as Jean Ziegler (2009) notes, if in the mystery of history, the wounded collective memory of peoples, suppressed for many centuries, takes over, it can be expected that what is the furthest away in time becomes the most active and influential element (Debray, 1976, as quoted by Ziegler, 2009, 
p. 34). It is suggested that this is the archaic element, historically the Age of the Mother Goddess, in which, according to Marija Gimbutas (1974), all archetypes are integrated in the sub-consciousness. She provided a list of 30,000 pre-historical artefacts, proving the Mother Goddess in all these archetypal manifestations (Queen, Warrior, Lover, Magician and Great Mother). Lietaer (2000) has therefore integrated the primordial archetype of the today mighty shadow of the Great Mother Goddess, whose yin-side he called 'mentality of need' and her yang-side 'mentality of greed', into Jung's Quaternion of Archetypes. There is an interesting phenomenon: The greater the disintegration of archetypal structure, or more profoundly the misbalance between them, the more it becomes obvious what the 'new science of chaos' (Briggs \& Peat, 1990) has found out: the creative aspect of change, transformation or evolution is not order, but disorder or chaos. Both possibilities of change were integrated in what Egyptians called the universal order Maat. Her symbols were either the two pans of the scales, counterbalancing each other, or a pendulum, oscillating from a centre. As soon as the utmost amplitude is reached, the pendulum swings into the opposite direction. The world which we experience with climate crisis, planetary emergencies and lately a global health crisis suggests that the pendulum has indeed reached a turning point. According to the 'order in chaos', recognized by the science of chaos (Briggs \& Peat, 1990) and by archetype psychology (Lietaer, 2000), is reached, when the ideals of the old order, made by humans, cannot anymore produce solutions, but only contrary results, creating even more chaos. Everything is turned upside-down: virtue becomes depravity, precaution dangerous and prudence madness (Paul Krugman. New York Times, quoted by Der Standard (Austria), 8. 11. 2008). If in such a critical point of time the human mind remains bound by a process of individualization, in which the 'I' only strives for enlargement to the own benefit, it remains oblivious to what the future needs, what has to be done or cannot be done. The future depends on the integration of the unconscious and the intuitive. The only way out is the free will of the people to bring into daylight the next possible integral structure of consciousness. This will be possible when the state of the mental structure has fulfilled its purpose to reach the fundamental differentiation and autonomy of humans and allows for a new synthesis at the next level of consciousness development. People then will transcend the current state and recognize that they are part of a whole. This brings to light an unexpected higher level of consciousness, which could not be understood before, because this is a creative act that collectively requires much more than planning a better future (Tarnas, 1991).

\subsection{A New Enlightenment}

In the presence of the great misbalance between a minority of very rich and the overwhelming majority of very poor people in our world, the psychotherapist Ron Smothermon (1986) called at the beginning of the decade of the 1980 for a 'New Enlightenment' in the world. This is connected with what was formerly called spiritual and is known today as transpersonal. According to Dane Rudhyar (1979), who introduced 
this term 1929 in the science of the soul, transpersonal means existing beyond the person in the sense of a conditioned and individualistic personality. While a personal attitude (or a personal feeling or a personal thought) is something which is rooted in the self (or 'I'), a transpersonal attitude is something, which emanates from the true non-binary, non-dualistic and nonlinear Self, using the personality only as instrument of manifestation (Rudhyar cited by Paul Krugman, 2008). However, if an enlightened individual of our days wants to ignore the ordinary world and tries to project his or her experience of universal love and harmony onto a world not ready for it, a duality crisis is the result. Somebody can spend the whole life trying to reach higher spheres of consciousness, while believing it is possible to maintain an altered state of consciousness uninterrupted all the time. Similar to the warning of the myth of a Greek hero and the snake-monster Medusa, this is as if one would seek the future by looking into a mirror, seeing a picture of a future state to achieve, and move towards it without recognizing it is only an image of the own self. Transformation requires the realization that the true state of wholeness and the joy and lightness a transpersonal state of mind grants, necessarily requires the integration of what one tries to leave behind. The way out of this dilemma is what Jung called individuation, which contrary to individualization is not understood in opposition to collective cares and obligations, but allows the integration of collective elements by the individual. Whatever way we choose as individual or as collective, whether self-renewal or self-destruction, the 'Law of Earth', still known by the Sumerian hero Enki, but not anymore by the first civilized hero Gilgamesh, will fulfil itself. It will fulfil itself according to the decisions of humanity in future decades, or according to the circumstances given to humanity to make decisions in future years. The question is, whether it will be possible for humanity to endure that power and to preserve it, in which the transformation of consciousness will become acute. The fate of humanity will depend on the intensity of consciousness, which humans shall reach and could reach, if they would succeed to live the transformation (Gebser, 1978). As soon as there is self-determination of sufficiently enough individuals to participate with their Selves in the process of anchoring the mind-change in human consciousness, GEIST-inAction can become self-conscious on the collective level (Wilber, 2001). The credo of an integral consciousness is not anymore the 'either-or', but the 'as-well-as', not the 'I', but the 'We'. It does not eliminate the ratio, but allows the human mind to expand in regions of a multi-dimensional reality. Because this structure of consciousness is able to comprehend not only the many local and time bound interpretations of the underlying universal principles, mythology can be shared by all people, because it originates out of time and space. The universal valid truth of the mythic structure of the mind can be revealed once more, but now enriched by a great knowledge of scientific details. This could become the end of exoteric wars between religions and believe systems. Finally, this emerging mind structure could give up the illusion of a never-ending material growth. Independent organizations like Amnesty International or Greenpeace are already examples for the new consciousness, likewise the liberation of women, the discourses around non-binary gender identities, and the search for new healing methods or new forms to live together. Moreover, the formation of independent networks, which do not centre around the egocentric of individuals, but 
around the democratic right of all humans, as well as social initiatives, are leading away from the madness of the shadow of the King and his addition to always being the first, the best, the richest and the most powerful man on earth.

Tristan (the modern man) may finally defeat the shadow-king, but before him lies the fight against the self-created monster. He cannot overcome it with the healing instrument of his mother, the harp (which stands for the archetypal Lover), but needs to allow the female archetype to rise not between the 'I' and the world, but between the 'I' and the sub-consciousness. The process of civilization requires the permanent absorption of unconscious elements in the psycho-mental body. This makes integration in the sense of the unification of parts to an entirety possible, while the reunification of polarities in the psyche is comparable to the 'psychological marriage' in mythology, which is necessary to transcend the intellect (Bergson, 1911). Combined with the growing inner feeling of a universality that shows reverence for pluraversality, more and more individuals will become conscious of the fact, that every human being represents a psycho-physical wholeness, which forms one with other entireties, be it with other people, nature or the universe. This allows the replacement of the feeling of separation and alienation by the secure knowledge to be 'at home in the universe' (Kauffman, 1996), to be within our self and within the world and to be in fact one with the world.

What is needed urgently is to integrate the 'universal power of self-renewal' in science and into approaches to overcome the climate crisis or other sustainability challenges. Only a 'new science of evolution', covering the range of the biological evolution and the evolution of consciousness (the dimensions of the history of civilization) simultaneously can overcome the analytic chaos of a scientific particularization and be filled instead with a meaning that is adequate to the natural needs of all beings, living today on the planet Earth. Only such a science, envisioned by Thompson (1985) as "Wissenskunst", can guarantee that science is not replaced by the egomania of the inner Magician or by phantasm. Only then will we begin to come closer to the realization of the ancient human dream: to co-create a world, in which humans can live in harmony with each other, with nature and with the universe.

\section{References}

Begg, E. (2006). The cult of the black virgin. Chiron Publications. ISBN 978-1-8886-0239-5. [First published by Penguin Arkana, London, 1985].

Bergson, H. (1911). Creative evolution. Chapter II. Henry Holt and Company.

Bohm, D. (1980). Wholeness and the implicate order. Routledge.

Paul Krugman. (2008). New York Times, quoted by Der Standard (Austria), 8 (11).

Boorstein, S. (Ed.) (1988). Transpersonale Psychotherapie. Neue Wege in der PsychotherapieTranspersonale Ansätze, Methoden und Ziele in der therapeutischen Praxis. Scherz.

Briggs, J., \& Peat, F. D. (1990). Die Entdeckung des Chaos. Hanser.

Brown, N. (1959). Life against death. Wesleyan University Press.

Campbell, J. (1968). Creative mythology. The masks of god. The Viking Press.

Campbell, J. (1992). Die Mitte ist überall. Kösel.

Campbell, J. (1996). Mythologie des Ostens. dtv. 
Capra, F., \& Luisi, P. L. (2014). The system's view of life: A unifying vision. Cambridge University Press.

Freud, S. (2017). Jenseits des Lustprinzips. CreateSpace Independent Publishing Platform.

Fromm, E. (1977). Anatomie der menschlichen Destruktivität. Rowohlt Taschenbuch.

Gebser, J. (1978). Gesamtausgabe. Band II. Ursprung und Gegenwart. Erster Teil. Das Fundament der aperspektivischen Welt. Beitrag zu einer Geschichte der Bewusstwerdung. Novalis Verlag AG.

Gimbutas, M. (1974). The goddesses and gods of old Europe, 7000-3500 B.C. Thames \& Hudson.

Harman, W. (1998). Global mind change: The promise of the 21st century. Berrett-Koehler Publishers.

Hillman, J. (2004). Archetypical psychology. Uniform Edition, vol. 1. Spring Publications.

Illies, J. (1978). Preface. In J. Gebser (Ed.), Gesamtausgabe. Band II. Ursprung und Gegenwart. Erster Teil. Das Fundament der aperspektivischen Welt. Beitrag zu einer Geschichte der Bewusstwerdung. Novalis Verlag AG.

Johnson, R. A. (1985). Traumvorstellung Liebe. Der Irrtum des Abendlandes. Olten.

Jung, C.G. (1983). Die Archetypen und das Kollektive Unbewusste. Gesammelte Werke. Band Neun/1. Walter.

Jung, C. G. (1995). Aion. Beiträge zur Symbolik des Selbst. Gesammelte Werke. Neunter Band. Zweiter Halbband. Sonderausgabe. Walter.

Kauffman, S. (1996). At home in the universe: The search for the laws of self-organization and complexity. Oxford University Press.

Kuenkel, P. (2008). Mind and heart: Mapping your personal journey towards leadership for sustainability. Collective Leadership Institute.

Lévy-Strauss, C. (1966). The savage mind. University of Chicago Press.

Lietaer, B. A. (2000). Mysterium Geld. Emotionale Bedeutung und Wirkungsweise eines Tabus. Riemann.

Oschman, W. (2016). Evolution der Erde. Geschichte des Lebens und der Erde. UTB.

Penrose, R. (1989). The emperors new mind. Oxford University Press. (London? 1989 original; 1991 Penguin Books)

Plato. (1973). Republic. In P. Shorey, Trans., E. Hamilton, \& H. Cairns (Eds.), The collected dialogues of Plato. Princeton University Press (Original work published 375 B.C.E.).

Powell, J. N. (1982). The tao of symbols. Morrow.

Powell, J. N. (1989). Das Tao der Symbole. Vom wahren Wesen unserer Sprache. Diederichs.

Prigogine, I. (1996). The end of certainty: Time chaos and the new laws of nature. The Free Press.

Rudhyar, D. (1979). Astrologie der Persönlichkeit. Ein neues Verständnis der astrologischen Konzepte in Bezug auf zeitgenössische Psychologie und Philosophie. Kailash Hugendubel.

Shear, J. (1981). Maharishi, Plato and the TM-Siddhi-program on innate structures of consciousness. Metaphilosophy, 12(1), 72-84.

Sheldrake, R. (1985). Das schöpferische Universum. Die Theorie des morphogenetischen Feldes. Meyster.

Smothermon, R. (1986). Drehbuch für Meisterschaft im Leben. Context.

Steffen, W., Crutzen, P. J., \& McNeill, J. R. (2007). The anthropocene: Are humans now overwhelming the great forces of nature? Ambio, 36(8), 614-621. https://doi.org/10.1016/j.gloenv cha.2015.09.01

Tarnas, R. (1991). The passion of the western mind. Understanding the ideas that have shaped our world view. Ballantine Books.

Thompson, W. I. (1985). Der Fall in die Zeit: Mythologie. Sexualität und der Ursprung der Kultur. Edition Weitbrecht Thienemann.

Vernadsky V. I. (1998). The biosphere. Translated and annotated version from the original of 1926. Springer, New York.

Vernadsky, V. I. (2006). Essays on geochemistry \&amp; the biosphere. Synergetic Press.

Wilber, K. (2001). Sex, ecology, spirituality: The spirit of evolution. Shambhala.

Woodroffe, S. J. G. (1974). The serpent power. Courier Corporation. 
Ziegler, J. (2009). Der Hass auf den Westen. Wie sich die armen Völker gegen den wirtschaftlichen Weltkrieg wehren. Bertelsmann.

Open Access This chapter is licensed under the terms of the Creative Commons Attribution 4.0 International License (http://creativecommons.org/licenses/by/4.0/), which permits use, sharing, adaptation, distribution and reproduction in any medium or format, as long as you give appropriate credit to the original author(s) and the source, provide a link to the Creative Commons license and indicate if changes were made.

The images or other third party material in this chapter are included in the chapter's Creative Commons license, unless indicated otherwise in a credit line to the material. If material is not included in the chapter's Creative Commons license and your intended use is not permitted by statutory regulation or exceeds the permitted use, you will need to obtain permission directly from the copyright holder.

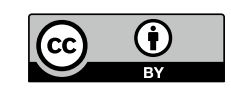

